\title{
Temperature Effects on Growth of Impatiens Plug Seedlings in Controlled Environments
}

\author{
David R. Dreesen ${ }^{1}$ and Robert W. Langhans ${ }^{2}$ \\ Department of Floriculture and Ornamental Horticulture, Cornell University, Ithaca, NY 14853
}

\begin{abstract}
Additional index words. Impatiens wallerana, bedding plant, net assimilation rate, leaf area ratio, irradiance, photosynthetic photon flux, mean relative growth rate, dry weight, height, leaf area

. Abstract. The objective of this study was to determine the dry weight, height, and leaf area growth responses of impatiens (Impatiens walerana Hook. f.) plug seedlings to air temperatures ranging from 18 to 29C. The conditions maintained in the controlled-environment growth rooms (CEGR) were ambient C0,levels, 24-h lighting, and photosynthetic photon flux (PPF) ranging from $\approx 215$ to $335 \mu \mathrm{mol} \cdot \mathrm{m}^{2}-\cdot \mathrm{s}^{-1} \cdot$. Mean daily temperatures of the plug medium ranged from 19.6 to 27.7C. At the higher PPF level, shoot dry weight decreased at plug medium temperatures (PMT) $>25 \mathrm{C}$; at lower PPF levels $\left(<300 \mu \mathrm{mol} \cdot \mathrm{m}^{-2} \cdot{ }^{-}{ }^{1}\right)$, shoot dry weight continued to increase with PMT $>25 \mathrm{C}$. The mean relative growth rate (MRGR) of shoot dry weight was positively correlated with PMT during the initial growth period (up to 14 days from sowing) and was negatively correlated thereafter. The maximum MRGR was predicted to occur at 11.7 days from sowing for a PMT of 19.6C, at 10.8 days for a PMT of 21.6C, and at 9.7 days for a PMT of 23.6C. Linear regression coefficients of shoot height as a function of PMT were substantially higher for seedlings grown at lower PPF than those for seedlings from the highest PPF level. Seedling leaf area consistently increased with increasing temperature. Net assimilation rate (NAR) decreased with increasing seedling age NAR increased with increasing PPF. A decrease in NAR was apparent at 29C relative to values at the lower temperatures. Leaf area ratio (LAR) declined with increasing seedling age and PPF; a quadratic relationship of LAR as a function of PMT indicates a minimum LAR at 22.5C. The seedlings grown at 29C were excessively tall, had thin succulent leaves, and were judged unacceptable for shipping and transplanting. Maximum quality indices (i.e., dry weight per height) were found at PMT of 24.3 to 25.0C for 10- to 14-day-old seedlings and at PMT of 23.0 to 24.OC for 16- to 20-day-old seedlings.
\end{abstract}

The production of horticultural crops in CEGR has not been adopted by commercial growers because high operating and capital costs constrain the types of crops that might be grown profitably. Plug seedlings of annual bedding plants satisfy some of the criteria that would allow profitable production in CEGR: a high crop value per unit of production area and a short production period. However, the growth response and quality of seedling crops produced in CEGR requires further elucidation to determine the potential for commercial application.

The heat load from the lighting system dominates the energy balance in CEGR. When the lamps are operating, cooling is accomplished by mechanical ventilation using outside air or air cooled by refrigeration. Seedling growth in CEGR can be limited by supra-optimal temperatures if the cooling capacity is insufficient or the cooling costs are exorbitant.

Krizek et al. $(1968,1974)$ reported greatly accelerated growth of bedding plant and vegetable seedlings using controlled-environment chambers. High irradiance, temperature, and $\mathrm{CO}_{2}$ levels yielded substantial increases in dry weight and leaf area, as well as precocious flower bud formation and increased lateral branch growth. Studies on the effects of light, temperature, and $\mathrm{CO}_{2}$ enrichment on seedling growth have been reported for tomato in prototype commercial growing rooms (Morgan et al.,

Received for publication 15 Apr. 1991. Accepted for publication 15 Aug. 1991. Research funded by a grant from the New York State Dept. of Agriculture and Markets. Equipment and supplies donated by Ivy Acres, BFG Supply Co., Harris Moran Seed Co., Ball Seed Co., H.G. German Seed Co., Vaughan's Seed, Co., and W. R. Grace Co. The cost of publishing this paper was defrayed in part by the payment of page charges. Under postal regulations, this paper therefore must be hereby marked advertisement solely to indicate this fact.

'Former Graduate Research Assistant; currently, Research Associate.

${ }^{2}$ Professor.

Abbreviations: CEGR, controlled-environment growth room; HI, high irradiance levels; LAR; leaf area ratio; LI, low irradianee levels; MHI, medium-high irradiance levels; MLI, medium-low irradiance levels; MRGR, mean relative growth rate; NAR, net assimilation rate; PMT, plug medium temperature; PPF, photosynthetic photon flux; QI, quality index.
1971); higher dry matter production was obtained at $26.5 \mathrm{C}$ than at 24 or $29.5 \mathrm{C}$. In studies on begonia (Begonia x sempeflorens-cultomm Hort.) seedlings, larger leaf area and higher dry weight were found at $27 \mathrm{C}$ than at $21 \mathrm{C}$ (Kessler and Armitage, 1989). There is a paucity of experimental results on the growth response of cotyledonary bedding plant seedlings to air and rootzone temperatures. In contrast, many studies can be found relating the response of older seedlings (i.e., seedlings transplanted into larger containers) to temperature (Merritt and Kohl, 1982,1985, 1989; Shedlosky and White, 1987; Welander, 1983). The size or age of the plant affects the optimum temperatures for plant growth, as reported for snapdragon (Miller, 1962).

The present study was part of a comprehensive investigation of the growth of bedding plant plug seedlings produced in CEGR. The results of initial studies to determine the uniformity of seedling growth response among growth rooms and over time have been reported (Dreesen and Langhans, 1991). The goal of the present study was to determine the growth response of 10- to 25-day-old impatiens seedlings to various temperature treatments under CEGR conditions (i.e., continuous lighting).

\section{Materials and Methods}

Details on the design and operation of the growth rooms have been reported (Dreesen and Langhans, 1991). A brief synopsis of important features of the seedling production system are reiterated below.

Growth rooms. The lighting system in the ceiling of each CEGR consisted of 15215-W cool-white fluorescent lamps (F96 PG17/CW; General Electric, Hendersonville, N. C.) mounted on $76-\mathrm{mm}$ centers in a $1.3 \times 2.5-\mathrm{m}$ frame covered with a $\mathrm{O} .1-\mathrm{mm}$ Tedlar (DuPont Co., Wilmington, Del.) polyvinylfluoride thermal barrier. The distribution of irradiance from the light system design was symmetrical. Low irradiance levels (LI) were measured in the four corners of the growing bench $(1.2 \times 2.4 \mathrm{~m})$ and high irradiance levels (HI) were measured in the four central plug tray positions. The irradiance levels at the tray positions 
along the edges of the bench were denoted medium-high (MHI) and medium-low irradiance (MLI) levels.

In each CEGR, two small fans (each with a flow rate of 0.06 $\mathrm{m}^{3} \cdot \mathrm{s}^{-}$) exhausted room air; a slotted air inlet was installed at floor level to provide entry of cool air. If necessary, heat could be supplied by a 1500-W electric heater in each CEGR. The exhaust fans and heaters were controlled by a computerized environmental control and data acquisition system (Keithley System 500, Cleveland). Air temperatures were measured with an aspirated solid-state sensor (constant current source integrated circuit). Two additional temperature sensors in each CEGR were inserted into the plug medium at two tray positions (HI and $\mathrm{LI}$ ) representing irradiance extremes.

The plug seedling trays were placed in an ebb-and-flood bench in each CEGR. The bench was flooded daily for 45 rein; the nutrient solution drained back to a 210 -liter polyethylene reservoir for reuse. The bench accommodated 16 plug trays (each $0.53 \mathrm{~m}$ long $\times 0.27 \mathrm{~m}$ wide) in a four tray $\times$ four tray arrangement.

Seedling culture. We selected 'Accent Red', one of the major cultivars being sold in the late 1980s. The seed was selected and graded by the seed company to provide high germination percentages ( $97 \%$ to $99 \%$ ) and uniform germination time.

The plug trays contained 512 tapered square cells. Each cell had a volume of $3 \mathrm{~cm}^{3}$, a $13 \times 13-\mathrm{mm}$ opening, and was 25 $\mathrm{mm}$ deep; the tray had 32 rows, each with 16 cells. The plug trays were filled with a dry commercial peatmoss and vermiculite medium (Terra-Lite Vegetable Plug. Mix; W.R. Grace Co., Cambridge, Mass.), compressed, and refilled. One lot of mix was used in all experiments (about one bag per experiment); appreciable differences in the nutrient charge were found between bags (Dreesen and Langhans, 1991).

The seed was sown with a compressed-air-operated vacuum seeder (Hamilton Natural Seeder, Burnham, England). After sowing, the trays were subirrigated to saturation and then misted. Seed was germinated in each CEGR under a polyethylene cover over the ebb-and-flood bench. The environmental conditions maintained under the cover during the germination phase were high relative humidity, moderate PPF (200 to $\left.300 \mu \mathrm{mol} \cdot \mathrm{m}^{-2} \cdot \mathrm{s}^{-}\right)$, 24-h lighting, air temperatures between 24 and 26C, and daily subirrigation with tap water. The cover was left in place until 4 days after sowing when radicles had emerged from the majority of seed; the experimental treatments were started when the cover was removed.

At the end of the germination period, nutrient stock solution was added to the water reservoir. The nutrient concentrations (in $\mathrm{mg} \cdot \mathrm{liter}^{-1}$ ) in the four CEGR at the start of the first temperature experiment averaged $141 \mathrm{NO}_{3}^{-} \mathrm{N}, 54 \mathrm{P}, 143 \mathrm{~K}, 168$ $\mathrm{Ca}, 13 \mathrm{Mg}, 0.40 \mathrm{Fe}, 0.13 \mathrm{Zn}, 0.05 \mathrm{~B}, 0.04 \mathrm{Mn}, 0.02 \mathrm{Cu}$, and 0.01 Mo. Because of inconsistent nutrient charges among bags of medium, the nutrient concentrations (except $\mathrm{P}$ ) in solution were increased by $30 \%$ in the second temperature experiment. Throughout the course of each individual experiment (20 to 25 days), no additional nutrients were added to replenish uptake losses. However, phosphoric acid was added initially and periodically (every 5 to 7 days) to maintain the solution $\mathrm{pH}$ between 5.5 and 6.5; the resulting solution concentration was generally between 40 and $60 \mathrm{mg}$ P/liter. Tap water was periodically added to replenish evapotranspiration.

Sampling and data collection. The sampling interval was 3 days, starting at Day 10 (10 days from sowing) when most of the cotyledons were fully expanded. Sampling for shoot dry weight and height was performed on the LI and HI trays 1 day before the MLI and MHI trays. Leaf area samples were taken the following day.

Details on the seedling sampling procedure are reported in Dreesen and Langhans (1991). The mean shoot dry weight for each tray was determined from the total dry weight divided by the number of seedlings sampled (sample size varied with age, e.g., from 55 to 75 seedlings comprised a sample on Day 10). One or two rows of seedlings were sampled from near the middle of each tray for leaf area measurement; typical sample sizes were $\approx 10$ and 25 seedlings for 19- and 10-day-old seedlings, respectively. The leaf area of a sample was determined with a LI-COR 3100 area meter (LI-COR, Lincoln, Neb.); the mean leaf area for an individual tray was determined by dividing the total sample leaf area by the number of seedlings in the sample. The mean height was determined from measurements of six to eight seedlings from each tray at each sampling.

Data analysis. The treatment means for shoot dry weight and height represent the mean of three replicate trays from the same irradiance level in each CEGR. The mean leaf area for a treatment represents a sample from only one tray from each irradiance level in each CEGR. First- (i.e., linear), second-, and third-degree polynomial regressions and stepwise multiple regressions were performed using Minitab statistical software (Minitab, 1988). The presence of significant deviations from second-degree polynomial regression resulting from the addition of the quadratic term was determined by calculating a deviation sum of squares using the method described by Snedecor and Cochran (1980). The reported coefficients of determination [i.e., $r^{2}$ (adj.)] are adjusted for degrees of freedom.

Quality index (QI) was calculated by dividing shoot dry weight (milligrams) by the seedling height (milliliters); a higher QI indicates a stockier seedling. The MRGR over a time interval $\left(\mathrm{t},-\mathrm{t}_{1}\right)$ was calculated as follows (Gardner et al. 1985): MRGR $=\left(\right.$ In $\mathrm{W}^{2}-$ In $\left.\mathrm{W},\right) /\left(\mathrm{t}_{2}-\mathrm{t}_{1}\right)$, where $\mathrm{W}=$ dry weight (milligrams) and $t=$ seedling age (days from sowing). Third-degree polynomial regressions of dry weight as a function of seedling age were calculated to derive derivatives $(\mathrm{dW} / \mathrm{dt})$ and predicted shoot dry weight for the seedling ages when leaf area data were taken (i.e., 12, 15, 18, and 21 days from sowing). These results allowed NAR and LAR to be calculated for specific seedling ages as follows: $\mathrm{NAR}=(\mathrm{l} / \mathrm{LA}) \times(\mathrm{dW} / \mathrm{dt})$ and $\mathrm{LAR}=\mathrm{LA} /$ $\mathrm{W}$, where LA = leaf area (square millimeters).

Experimental design. The experiments examining the influence of temperature on impatiens seedling growth were conducted using the following environmental conditions: 24-h continuous lighting, 9-h day temperature, 15-h night temperature, and ambient $\mathrm{CO}_{2}$. The night/day heating setpoints for the five treatments were as follows: 18/18C, 18/23C, 21/26C, and $23 / 23 \mathrm{C}$ (in the first experiment) and $29 / 29 \mathrm{C}$ (in the second experiment). The cooling setpoints were $1 . \mathrm{OC}$ higher than the heating setpoints. The $21 / 26 \mathrm{C}$ and $23 / 23 \mathrm{C}$ treatments had similar 24-h average temperatures and were included to examine the effect of fluctuating temperature. The PPF was fixed by a lamp to plug distance of $0.61 \mathrm{~m}$; this arrangement resulted in PPF values averaging $\approx 215 \mu \mathrm{mol} \cdot \mathrm{m}^{-2} \cdot \mathrm{s}^{-1}$ at LI and 335 $\mu \mathrm{mol} \cdot \mathrm{m}^{-2} \cdot \mathrm{s}^{-1}$ at $\mathrm{HI}$. The growth room used for the $23 / 23 \mathrm{C}$ treatment had $10 \%$ lower PPF as a result of older lamps. The PPF was measured in all tray midpoints (i.e., 16 points in each CEGR) using a LI-COR 185 irradiance meter and quantum sensor at the beginning and end of each experiment.

Earlier studies investigated whether intrinsic differences between growth rooms would result in significantly different growth response when nearly identical baseline environmental condi- 
ions were imposed (Dreesen and Langhans, 1991). In addition, one growth room in each of seven experiments was maintained at the baseline conditions to track seedling growth response over time. The results revealed no general pattern of particular CEGR affecting dry weight, height, or leaf area growth. For those few instances where significant differences were found, the cause appears to be nonuniform PPF among the growth rooms. Consistent shoot dry weight growth was observed among experiments with nearly identical baseline treatments, indicating that predictable and repeatable seedling growth could be achieved over time.

\section{Results and Discussion}

Measurements of environmental conditions. Night, day, and 24-h mean air and PMT are presented in Table 1. The 24-h temperatures are weighted averages based on 9-h day and 15-h night periods. The $24-\mathrm{h}$ means for the $21 / 26 \mathrm{C}$ and the $23 / 23 \mathrm{C}$ treatments are similar, allowing the comparison of a fluctuating with a constant temperature regime with the same 24-h average temperature. The standard errors of the mean temperatures based on 20 daily means were usually 0.1 to $0.2 \mathrm{C}$. The mean air temperatures maintained were 0.4 to $0.7 \mathrm{C}$ higher than the heating setpoint in the low-temperature treatments (18 and $21 \mathrm{C})$. At intermediate temperature $(23 \mathrm{C})$, the maintained temperatures were very close to the heating setpoints; at the high temperatures (26 and $29 \mathrm{C}$ ), the maintained temperatures were 0.1 to $0.7 \mathrm{C}$ below the heating setpoint. The PMT achieved was consistently higher in the HI tray positions than the LI; the temperature differences ranged up to $1.8 \mathrm{C}$ in the $29 / 29 \mathrm{C}$ treatment. The measured air temperatures were generally less than PMT, except in the highest temperature treatment $(29 / 29$ C). For those treatments with similar night or day setpoints (i.e., $18 / 18 \mathrm{C}$ and $18 / 23 \mathrm{C}$ at night, $18 / 23 \mathrm{C}$ and $23 / 23 \mathrm{C}$ during the day), the measured air temperatures were no more than $0.2 \mathrm{C}$ different for corresponding treatments and PMT were within 0.4C, except for the HI night PMT in the $18 / 23 \mathrm{C}$ treatment. The heat retention of the tray and medium could have caused the higher than expected night PMT in this treatment.

The PPF data (Table 1) show fairly consistent irradiance levels among treatments, except for $23 / 23 \mathrm{C}$, which was conducted in a growth room with older fluorescent lamps.

Effects of temperature on shoot dry weight growth. Linear and second-degree polynomial regressions were derived for shoot dry weight as a function of 24-h air temperature or 24-h PMT. Only regressions using PMT as the independent variable are presented (Fig. 1 a and b) because of the similarities in $r^{2}$ (adj.) for regressions using either air or PMT. Only regressions using $\mathrm{HI}$ and LI seedling dry weights have been presented because the regressions for the MLI and MHI data exhibited relationships intermediate between the HI and LI regressions.

The linear regressions of shoot dry weight as a function of PMT were highly significant $(\mathrm{P}<0.001)$ for all seedling ages and for all irradiance levels, except the HI seedlings. For the LI, MLI, and MHI seedlings, linear regressions explained more than $70 \%$ of the variation in dry weight (except MHI Day 20 with 58\%). However, small but significant improvements in explained sum of squares were achieved by adding a quadratic term. Thus, a diminishing increase in dry weight as a function of PMT is evident for the younger seedlings (Day 10-16) at the low and intermediate irradiance levels.

The 10- to 19-day-old HI seedlings have nonsignificant $(\mathrm{P}>$ 0.05 for Day 16$)$ or low significance $(0.01<\boldsymbol{P}<\mathbf{0 . 0 5}$ for Day 10, 13, and 19) linear regressions (Fig. la). The addition of a quadratic term resulted in large increases in the explained sum of squares for HI seedling regressions [i.e., $r^{2}$ (adj.) for linear regressions ranged from 0.16 to $0.39 ; r^{2}$ (adj.) with quadratic term ranged from 0.65 to 0.86]. Supra-optimal PMT are evident in the 29/29C treatment (27.7C) for HI seedlings (Fig. la, Days 16 and 19). Maximum dry weights for HI seedlings have been predicted at PMT between 24.6 and 25.2C (derived by setting

Table 1. Mean air and plug medium temperatures for the five temperature treatments based on 20 daily means of 15 -min average temperatures. Mean PPF at the start of the experiments at the four irradiance levels.

\begin{tabular}{|c|c|c|c|c|c|}
\hline \multirow{2}{*}{$\begin{array}{l}\text { Time } \\
\text { and } \\
\text { irradiance }\end{array}$} & \multicolumn{5}{|c|}{ Temp treatments $\left({ }^{\circ} \mathrm{C}\right)$} \\
\hline & $18 / 18$ & $18 / 23$ & $21 / 26$ & $23 / 23$ & $29 / 29$ \\
\hline & \multicolumn{5}{|c|}{ Mean air temp $\left({ }^{\circ} \mathrm{C}\right)$ and $(S E)$} \\
\hline Night & $18.4(0.1)$ & $18.6(0.1)$ & $21.7(0.2)$ & $23.1(0.1)$ & $28.3(0.1)$ \\
\hline Day & $18.7(0.2)$ & $23.0(0.1)$ & $25.9(0.1)$ & $23.1(0.1)$ & $28.5(0.1)$ \\
\hline \multirow[t]{2}{*}{$24 \mathrm{~h}^{\mathrm{z}}$} & 18.5 & 20.3 & 23.3 & 23.1 & 28.4 \\
\hline & \multicolumn{5}{|c|}{ Mean plug medium temp $\left({ }^{\circ} \mathrm{C}\right)$ and (SE) } \\
\hline \multicolumn{6}{|c|}{ 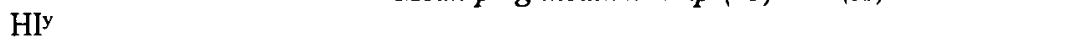 } \\
\hline Night & $19.6(0.1)$ & $21.2(0.1)$ & $23.1(0.1)$ & $23.9(0.1)$ & $27.7(0.2)$ \\
\hline Day & $19.8(0.2)$ & $24.0(0.1)$ & $25.8(0.1)$ & $23.8(0.2)$ & $27.6(0.1)$ \\
\hline $24 \mathrm{~h}$ & 19.7 & 22.3 & 24.2 & 23.9 & 27.7 \\
\hline \multicolumn{6}{|l|}{$L^{y}$} \\
\hline Night & $19.5(0.2)$ & $19.9(0.2)$ & $22.1(0.1)$ & $23.2(0.1)$ & $25.9(0.3)$ \\
\hline Day & $19.6(0.2)$ & $22.6(0.2)$ & $24.8(0.1)$ & $23.0(0.2)$ & $26.0(0.3)$ \\
\hline $24 \mathrm{~h}$ & 19.6 & 20.9 & 23.1 & 23.2 & 26.0 \\
\hline & \multicolumn{5}{|c|}{ Mean PPF× $\left(\mu \mathrm{mol} \cdot \mathrm{m}^{-2} \cdot \mathrm{s}^{-1}\right)$} \\
\hline LI & 220 & 229 & 215 & 198 & 224 \\
\hline MLIy & 258 & 272 & 251 & 231 & 267 \\
\hline $\mathrm{MHI}^{y}$ & 286 & 296 & 276 & 254 & 291 \\
\hline $\mathrm{HI}$ & 341 & 360 & 332 & 302 & 349 \\
\hline
\end{tabular}

${ }^{\mathrm{z}}$ Weighted 24 -h average based on 9 -h day and 15 -h night.

YIrradiance levels at the four plug tray positions.

xMean based on four PPF measurements at each irradiance level. 

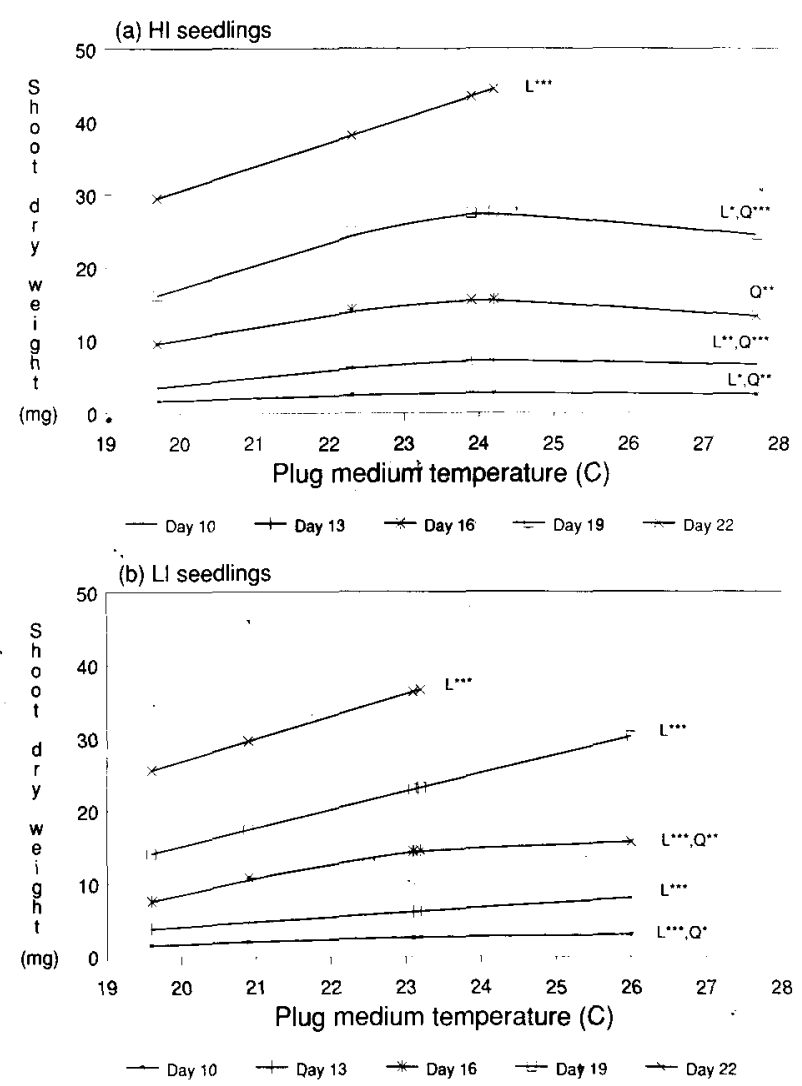

Fig. 1. Regressions of shoot dry weight of impatiens seedlings as a function of plug medium temperature for seedling ages from 10 to 22 days (from sowing). Data points represent predicted dry weight from regression. Significance levels for linear regression $(\mathrm{L})$ alone or with quadratic term added $(\mathrm{Q}): P<0.05\left({ }^{*}\right), 0.01\left({ }^{* *}\right)$, or 0.001 $\left({ }^{* * *}\right)$. Seedlings grown at two irradiance levels $\left(\mathrm{PPF}\right.$ in $\left.\mu \mathrm{mol} \cdot \mathrm{m}^{-2} \cdot \mathrm{s}^{-1}\right)$ : (a) HI (302 to 360) and (b) LI (198 to 229).

the derivatives of the second-degree polynomial regression equations equal to zero). Similar calculations for the LI, MLI, and MHI regressions with significant quadratic terms yielded optimum PMT ranging from 25.5 to $28.2 \mathrm{C}$. Because different irradiance levels result in different PMT, supra-optimal temperatures will depend on tray position in the CEGR. At high $\operatorname{PPF}\left(\approx 335 \mu \mathrm{mol} \cdot \mathrm{m}^{-2} \cdot \mathrm{s}^{-1}\right)$, the optimal PMT is $\approx 25 \mathrm{C}$ under the environmental conditions imposed in these experiments. At low PPF $\left.\Leftarrow 215 \mu \mathrm{mol} \cdot \mathrm{m}^{-2} \cdot \mathrm{s}^{-1}\right)$, shoot dry weight is still increasing at PMT of $26 \mathrm{C}$.

Analysis of variance (ANOVA) of dry weight between the $21 / 26 \mathrm{C}$ and $23 / 23 \mathrm{C}$ treatments revealed no significant differences $(\mathrm{P}>0.05)$ for fluctuating vs. constant temperature regimes having similar $24-\mathrm{h}$ average temperatures. However, 18 of 20 comparisons of means showed a higher shoot dry weight under constant temperature even though the CEGR used for the 23/23C treatment had substantially lower PPF. The trend of higher shoot dry weight in the constant temperature treatment indicates a possible detriment due to fluctuating temperatures. Morgan et al. (1971) found a higher dry weight for tomato seedlings grown in a $26.5 / 26.5 \mathrm{C}$ (night/day) temperature regime than in a $24 / 29.5 \mathrm{C}$ regime; they found no differences in dry weight between $21 / 21 \mathrm{C}$ and $19 / 23 \mathrm{C}$ regimes. Under our experimental conditions with continuous lighting, no photosynthetic benefit from thermoperiodicity would be expected.

The nutrient solution used in the $29 / 29 \mathrm{C}$ treatment (i.e., second experiment) had a nutrient level $\approx 30 \%$ higher than that used in the first experiment. This change was made to mask the effects of nonuniform nutrient levels in the plug medium but also resulted in growth enhancement. This difference in nutrient solutions could account for some portion of the dry weight increase found for 29/29C seedlings compared with LI, MLI, and MHI seedlings grown at intermediate temperatures. A comparison of LI shoots grown in the two experiments under identical baseline conditions (i.e., 18/23C temperature setpoints) shows an average dry weight increase of $31 \% \pm 5 \%$ SD for various seedling ages as a result of higher nutrient levels in the second experiment. The 29/29C treatment produced LI shoots $60 \% \pm$ $11 \%$ SD heavier than those produced at the baseline temperature treatment $(18 / 23 \mathrm{C})$ when both had high nutrient levels. Therefore, a substantial portion of the increased dry weight in the LI 29/29C treatment could have resulted from improved nutrition. A similar comparison of $\mathrm{HI}$ seedlings under baseline conditions in the two experiments shows a $14 \% \pm 9 \%$ sD increases in dry weight in the second experiment due to higher nutrient levels. The HI shoot dry weights decreased an average of $6 \% \pm 6 \%$ SD when comparing the $18 / 23 \mathrm{C}$ with the $29 / 29 \mathrm{C}$ treatment; these results indicate that dry-weight decreases resulted from supraoptimal temperatures. Therefore, it is reasonable to assume that the dry-weight data are probably overestimating optimal plug temperatures for LI treatments because of the higher than expected dry weights in the $29 / 29 \mathrm{C}$ treatment due to better nutrition.

Kessler and Armitage (1989) found appreciably higher dry weight for begonia seedlings with air at 27C than at $21 \mathrm{C}$ at PPF of 220 to $320 \mu \mathrm{mol} \cdot \mathrm{m}^{-2} \cdot \mathrm{s}^{-1}$ and controlled-environment treatment times of 2 and 4 weeks. Hussey (1965) found the greatest dry-weight increase with air at $25 \mathrm{C}$ for tomato (Lycopersicon esculentum Mill) seedlings in the first 9 days after the cotyledons had become horizontal. In another study with tomato seedlings, higher dry weight was achieved at $26.5 \mathrm{C}$ than at 24 or 29.5C (Morgan et al., 1971). Seginer and Raviv (1984) predicted highest growth rates for tomato seedlings in the first 5 weeks of growth at 22 to $23 \mathrm{C}$. Our results show optimal growth of impatiens seedlings at $\approx 25 \mathrm{C}$ for moderately high irradiance levels.

MRGR for shoot dry weight. The MRGR for shoot dry weight was determined for each individual tray. The mean MRGR data were determined from 12 trays in each temperature treatment (i.e., three replicate trays from each of the four irradiance levels); for each growth period, linear and second-degree polynomial regressions of MRGR as a function of 24-h PMT were calculated (Fig. 2). The first growth period was assumed to start at Day 4 when radicle emergence began. The average initial seed dry weight was $0.66 \mathrm{mg}$. Measurements of 7-day-old seedlings showed that the hypocotyl comprised $75 \%$ of total seedling dry weight; therefore, an initial shoot dry weight of $0.5 \mathrm{mg}$ was used in MRGR calculations for the first growth period (i.e., Days 4-11). The second-degree polynomial regression for the first growth period (quadratic term $P<0.01$ ) showed diminishing increases in MRGR (in units of $\mathrm{d} 1$, which are equivalent to $\mathrm{mg} \cdot \mathrm{day}^{-1} \cdot \mathrm{mg}^{-1}$, with increasing PMT (C) and a maximum MRGR at 25.6C: MRGR $=-1.605+0.149 \mathrm{PMT}-$ $0.002915 \mathrm{PMT}^{2}$. During the second growth period (Days 1014), the trend of increasing MRGR with temperature continued, but the slope of the regression line was only one-third of that found for the linear regression for the first growth period (i.e., 0.0041 vs. $0.0132 \mathrm{~d}^{-1} / \mathrm{C}^{-1}$ ). By the third growth period (Fig. 2b, Days 13-17), then MRGR showed a significant decline $(P$ $<0.05)$ as PMT increased: MRGR $=0.384-0.00572 \mathrm{PMT}$. 
(a) Periods: $4-11$ and $10-14$ days
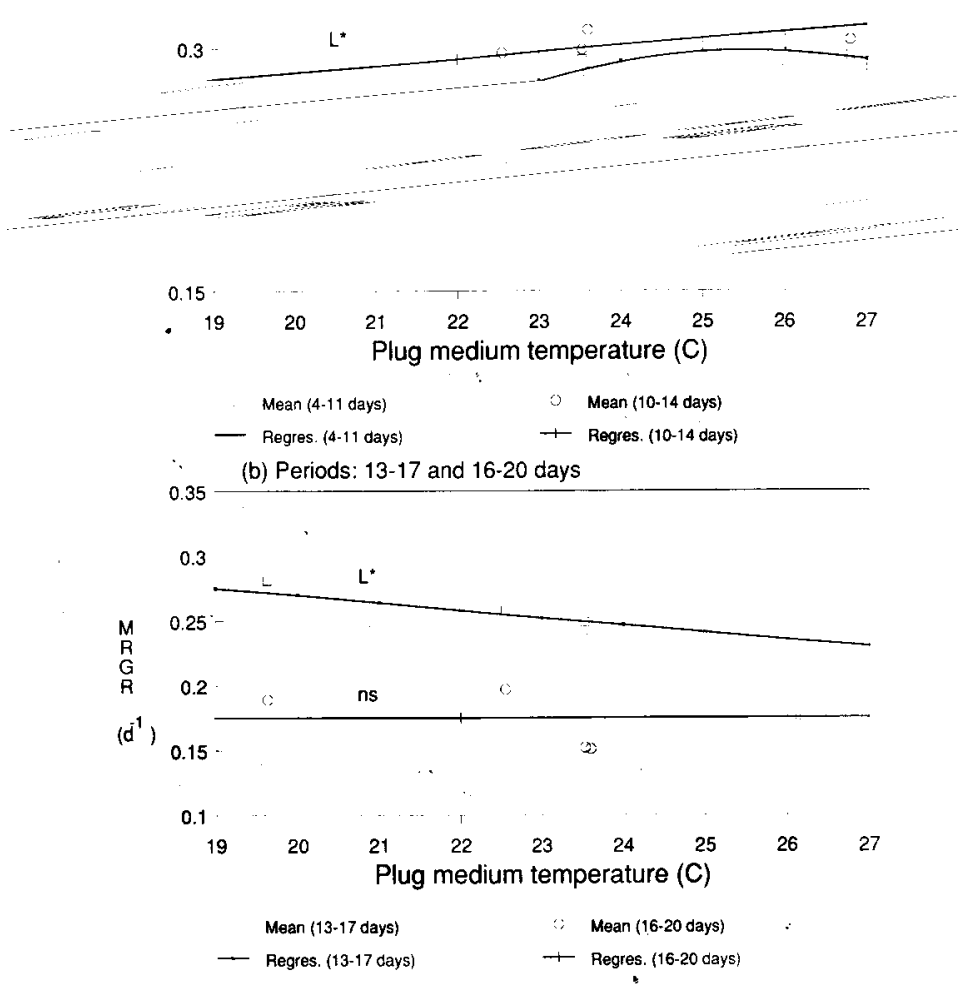

Fig. 2. MRGR of impatiens seedling shoot dry weight as a function of plug medium temperature for growth periods (a) Days 4-11 and 10-14 and (b) Days 13-17 and 16-20 (from sowing). Data points represent mean MRGR $(n=12)$. Significance levels for linear regression (L) alone or with quadratic term added (Q): $P>0.05$ (ns), $P<0.05\left(^{*}\right), 0.01\left(^{* *}\right)$, or $0.001\left(^{* * *}\right)$.

During the fourth growth period (Days 16-20), the first- and second-degree polynomial regressions were not significant $(P$ $>0.05$ ).

These results suggest that the timing of the maximum MRGR depends on temperature. Therefore, second-degree and thirddegree polynomial regressions of MRGR as a function of seedling age were calculated for each temperature treatment; seedling age was defined as the midpoint of the growth period (e.g., for the 4-to 11-day period, the seedling age used was 7.5 days). The addition of the cubic term was significant for the $18 / 18 \mathrm{C}$, $18 / 23 \mathrm{C}, 21 / 26 \mathrm{C}$, and 23/23C treatments with $r^{2}$ (adj.) for the third-degree polynomial regressions of $0.74,0.89,0.96$, and 0.87 , respectively. The cubic term did not increase the explained sum of squares for the $29 / 29 \mathrm{C}$ treatment; the seconddegree polynomial regression yielded an $r^{2}$ (adj.) of 0.85 . The age of maximum MRGR was estimated by setting the derivative of the regression equations equal to zero. The maximum MRGR is predicted at $11.7,10.8,9.9,9.7$, and 9.6 days from sowing for the $18 / 18 \mathrm{C}, 18 / 23 \mathrm{C}, 21 / 26 \mathrm{C}, 23 / 23 \mathrm{C}$, and $29 / 29 \mathrm{C}$ treatments, respectively. The $21 / 26 \mathrm{C}$ and $23 / 23 \mathrm{C}$ treatments had nearly identical 24 -h average temperatures and nearly identical seedling ages for the occurrence of maximum MRGR. In addition to temperature effects, the derived seedling age for maximum MRGR in the 29/29C treatment may have been affected by the increased nutrient levels present in the second experiment. These results suggest that the timing of maximum MRGR in seedling crops depends on temperature; cooler temperatures delay the occurrence of the highest relative growth rates.
Effect of temperature on shoot height. The addition of a negative quadratic term to regressions of HI and LI seedling height as a function of PMT (Fig. 3) (i.e., diminishing increases in height with PMT) significantly $(\mathrm{P}<0.05)$ increased the explained sum of squares in only two of 20 second-degree polynomial regressions. Within the studied temperature range, there was no consistent trend of a diminishing increase in height as temperature increased. Two instances of accelerating increases (i.e., positive quadratic terms) in height with increasing PMT were found for the older LI seedlings (Day 16 and 19, Fig. 3b).

Examination of the regression statistics reveals consistently steeper slopes for the LI than for the HI seedlings; the linear coefficients (millimeters per ${ }^{\circ} \mathrm{C}$ ) for LI seedlings range from $67 \%$ to $172 \%$ higher than those of the HI seedlings of the same age. The predicted heights of LI seedlings at PMT of 20, 22.5, and $25 \mathrm{C}$ are $2 \%, 7 \%$, and $18 \%$ greater, respectively, than those for HI seedlings (averaged for Day 10-19 seedlings).

Increased height growth at high temperatures is especially apparent for the 16- to 20-day-old seedlings; at this age, competition among seedlings for light may enhance height growth. The higher nutrient levels in the 29/29C treatment may have been partially responsible for increased shoot height. The height increments for Day 16 and 19 seedlings resulting from the increased nutrients averaged 2.5 to $2.6 \mathrm{~mm}$ for LI seedlings and 0.9 to $1.3 \mathrm{~mm}$ for HI seedlings in the baseline treatments (Dreesen and Langhans, 1991). The height increment comparing 18/ 23C (i.e., baseline) and 29/29C treatments were 6.7 to $9.1 \mathrm{~mm}$

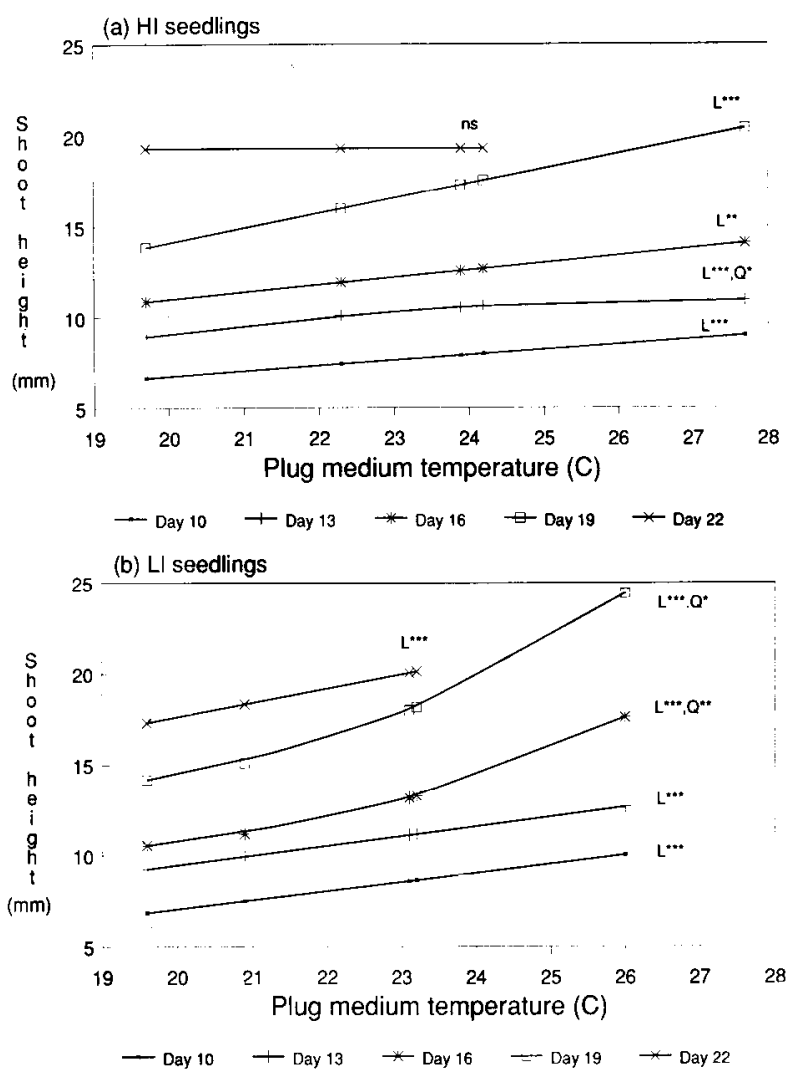

Fig. 3. Regressions of shoot height of impatiens seedlings as a function of plug medium temperature for seedling ages from 10 to 22 days (from sowing). Data points represent predicted height from regression. Significance levels for linear regression (L) alone or with quadratic term added (Q): $P>0.05(\mathrm{~ns}), P<0.05\left(^{*}\right), 0.01\left(^{* *}\right)$, or $0.001\left(^{* * *}\right)$. Seedlings grown at two irradiance levels (PPF in $\left.\mu \mathrm{mol} \cdot \mathrm{m}^{-2} \cdot \mathrm{s}^{-1}\right)$ : (a) HI (302 to 360) and (b) LI (198 to 229). 
for LI seedlings and 2.1 to $2.8 \mathrm{~mm}$ for HI seedlings. These results indicate that seedling nutrition could have accounted for some fraction of the height increase found at high PMT.

The height growth increment at high temperatures would probably be considered a detriment to market quality rather than a benefit; the buyer of plug seedlings is generally looking for stocky instead of lanky seedlings for transplanting into larger containers. Regression analyses of the QI as a function of PMT (Fig. $4 \mathrm{a}$ and $\mathrm{b}$ ) showed significant quadratic terms for most seedling ages and both irradiance levels. The maximum QI predicted by the second-degree polynomial regressions was calculated at PMT between 24.3 and $25.0 \mathrm{C}$ for 10- to 14-day-old seedlings (six regressions including MHI and MLI data) and between 23.0 and $24.0 \mathrm{C}$ for 16- to 20-day-old seedlings (seven regressions including MHI and MLI data).

ANOVA comparing the seedling height between the $21 / 26 \mathrm{C}$ and $23 / 23 \mathrm{C}$ treatments show significantly $(P<0.05)$ taller seedlings for the $23 / 23 \mathrm{C}$ treatment for seedling ages of 17 (HI and LI) and 19 days (MLI and MHI). The trend of taller seedlings in the constant vs. the fluctuating temperature treatment is evident for other seedling ages but is not statistically significant (17 of 20 comparisons show taller seedlings in the 23/23C treatment). The occurrence of taller seedlings in the constant temperature regime with 24-h lighting may reflect 1) an etiolation effect from the $10 \%$ lower PPF in this growth room or 2) the greater shoot dry-weight growth in the constant temperature
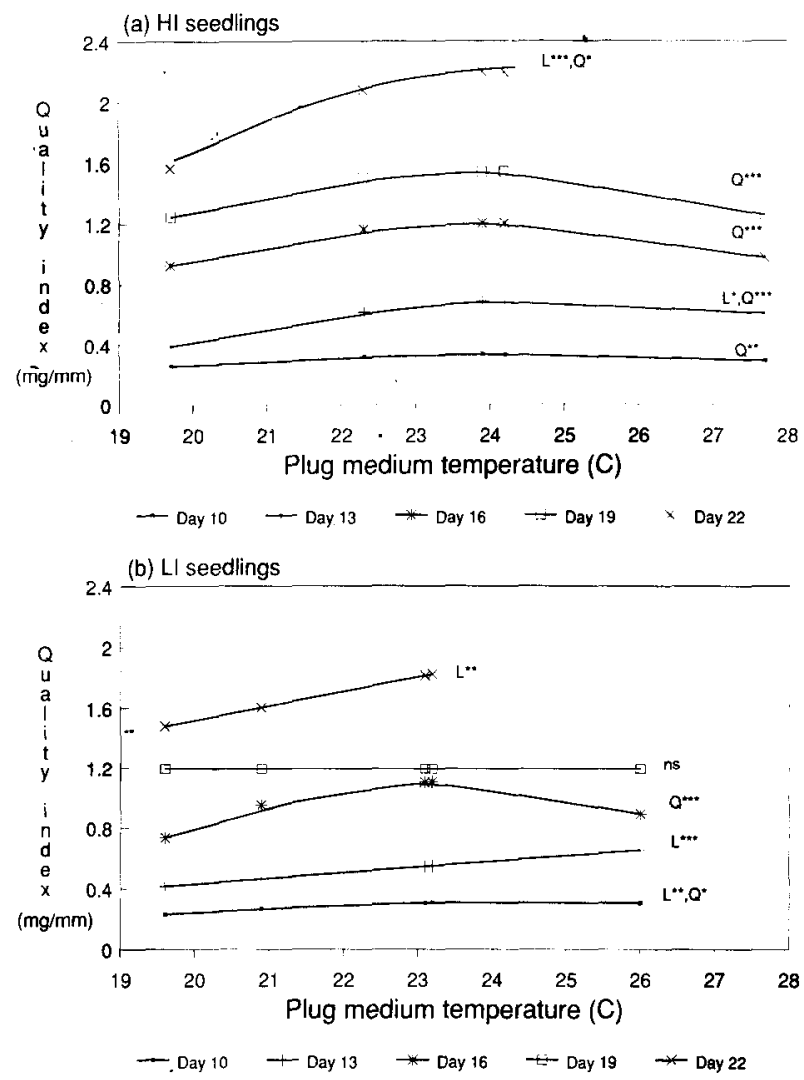

Fig. 4. Regressions of $\mathrm{QI}$ of impatiens seedlings as a function of plug medium temperature for seedling ages from 10 to 22 days (from sowing). QI calculated from shoot weight $(\mathrm{mg})$ divided by height $(\mathrm{mm})$. Data points represent predicted QI from regression. Significance levels for linear regression (L) alone or with quadratic term added (Q): $P>0.05(\mathrm{~ns}), P<0.05\left(^{*}\right), 0.01\left(^{* *}\right)$, or $0.001\left({ }^{* *}\right)$. Seedlings grown at two irradiance levels (PPF in $\left.\mu \mathrm{mol} \cdot \mathrm{m}^{-2} \cdot \mathrm{s}^{-1}\right)$ : (a) HI (302 to 360) and (b) LI (198 to 229). treatment described previously. Morgan et al. (1971) found shorter tomato seedlings at $26.5 / 26.5 \mathrm{C}$ vs. $24.0 / 29.5 \mathrm{C}$ with a dark period during the night.

Effect of temperature on leaf area. The regression lines/curves of first- and second-degree polynomials of seedling leaf area as a function of PMT in low- (LI and MLI) and high-irradiance (HI and MHI) environments show a trend of decreasing effect of temperature on leaf area as irradiance level increases (i.e., smaller linear coefficients as irradiance increases) (Fig. 5). As early as Day 12, a 1C increase in plug temperature will result in a $14-\mathrm{mm}^{2}$ increase in leaf area (pooled data from all irradiance levels). By Day 21, this increment in leaf area per degree $\mathrm{C}$ is $73 \mathrm{~mm}^{2}$.

These results emphasize the importance of higher temperatures in early seedling stages to maximize leaf area and the resulting interception of photosynthetically active radiation. Similar results with begonia seedlings have been reported; leaf area growth was much greater at $27 \mathrm{C}$ than at $21 \mathrm{C}$ for plants grown for 2 and 4 weeks in various light and $\mathrm{CO}_{2}$ regimes (Kessler and Armitage, 1989).

$N A R$ and LAR. NAR and LAR were calculated using leaf area measurements, predicted seedling dry weights, and rates of dry-weight change $(\mathrm{dW} / \mathrm{dt})$ for seedling ages of $12,15,18$, and 21 days. The effect of PMT, seedling age, and PPF on NAR was investigated using stepwise multiple regression analysis: NAR $\left(\mathrm{mg} \cdot \mathrm{mm}^{-2} \cdot \mathrm{d}^{-1}\right)=(972-1.38$ AGE $\times$ PMT + 1.48PPF $) \times 10^{-5} ; r^{2}(a d j)=$.0.55 , where AGE $=$ seedling age (days from sowing), PPF $=\mu \mathrm{mol} \cdot \mathrm{m}^{-2} \cdot \mathrm{s}^{-1}$, and PMT $=$ "C. F tests for terms in the regression equation were significant at $P<0.01$; only one interaction term (AGE $\times$ PMT) was significant.

The calculated NAR (not predicted from the above equation) of impatiens seedlings declined substantially with age from 1010 $\times 10^{-5} \mathrm{mg} \cdot \mathrm{mm}^{-2} \cdot \mathrm{d}^{-1}$ at Day 12 to $730 \times 10^{-5} \mathrm{mg} \cdot \mathrm{mm}^{-2} \cdot \mathrm{d}^{-1}$ at Day 21. This decline may reflect increased intraplant and interplant shading for older seedlings. Higher irradiance resulted in larger NAR: $930 \times 10^{-5}$ compared with $770 \times 10^{-5}$ $\mathrm{mg} \cdot \mathrm{mm}^{-2} \cdot \mathrm{d}^{-1}$ in the HI vs. the LI seedlings. The NAR at relatively low temperatures $(18 / 18 \mathrm{C}$ and $18 / 23 \mathrm{C})$ ranged from 880 to $910 \times 10^{-5} \mathrm{~m} \mathrm{~g} \cdot \mathrm{m} \mathrm{m}^{-2} \cdot \mathrm{d}^{-1}$ compared with $710 \times 10^{-5}$ $\mathrm{mg} \cdot \mathrm{mm}^{-2} \cdot \mathrm{d}^{-1}$ in the $29 / 29 \mathrm{C}$ treatment; ANOVA among temperature treatments revealed a significant difference in NAR $(P$ $<0.05$ ) between the $29 / 29 \mathrm{C}$ treatment and the $18 / 18 \mathrm{C}, 18 / 23 \mathrm{C}$,

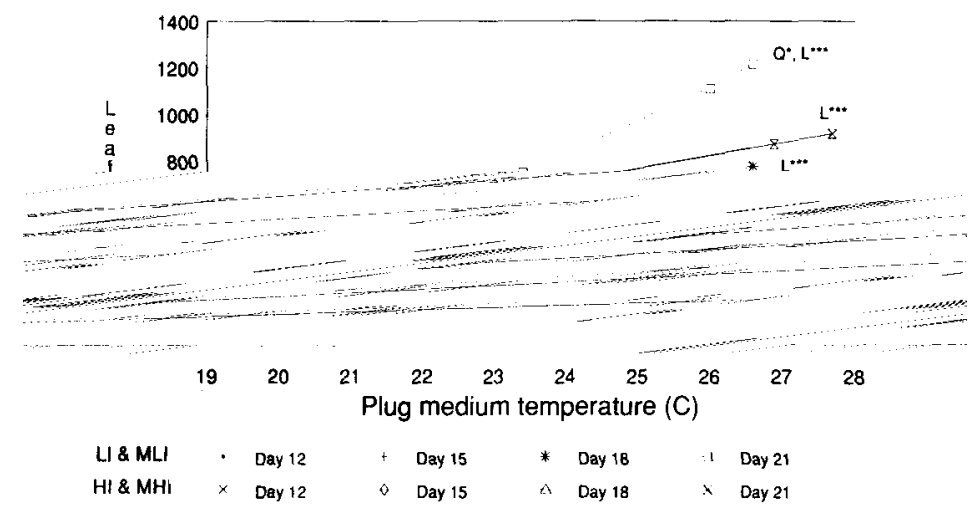

Fig. 5. Regressions of leaf area of impatiens seedlings as a function of plug medium temperature for seedling ages of $12,15,18$, and 21 days grouped by irradiance level (PPF in $\mu \mathrm{mol} \cdot \mathrm{m}^{-2} \cdot \mathrm{s}^{-1}$ ): $\mathrm{HI}(302$ to 360 ) and MHI (254 to 296); MLI (231 to 272) and LI (198 to 229). Significance levels for linear regression (L) alone or with quadratic term added $(\mathrm{Q}): P<0.05\left(^{*}\right), 0.01\left(^{* *}\right)$ or $0.001\left(^{* * *}\right)$.

J. Amer. Soc. Hort. Sci. 117(2):209-215. 1992. 
and $21 / 26 \mathrm{C}$ treatments. When data from the $29 / 29 \mathrm{C}$ treatment are deleted from the stepwise regression, the NAR becomes strictly a function of seedling age and irradiance (not PMT): NAR $\left(\mathrm{mg} \cdot \mathrm{mm}^{-2} \cdot \mathrm{d}^{-1}\right)=(883-29.8 \mathrm{AGE}+1.76 \mathrm{PPF}) \times$ $10^{-5} ; r^{2}($ adj. $)=0.55$.

The trends of NAR as a function of environmental variables for impatiens seedlings are consistent with other studies. Warren-Wilson (1966) found NAR to vary little over wide temperature ranges for sunflower (Helianthus armuus L.), maize (Zea mays L.), and rape (Bras.sica napus L.). A study on the growth of Impatiens parviflora DC. showed increasing NAR at higher irradiance and a decline in NAR with plant age (Hughes, 1965). Hurd and Thornley (1974) found a positive correlation between NAR and light integral for tomato seedlings grown in controlled environments.

Stepwise multiple regression analysis of LAR as a function of PMT, seedling age, and irradiance yielded: LAR $\left(\mathrm{mm}^{2} \cdot \mathrm{mg}^{-1}\right)$ $=227-1.06 \mathrm{AGE}-0.0424 \mathrm{PPF}-15.5 \mathrm{PMT}+0.345 \mathrm{PMT}^{2}$; $r^{2}(a d j)=$.0.77 . $\mathrm{F}$ tests for all terms in the regression equation are significant at $P<0.001$. The inclusion of interaction terms between the three independent variables did not increase the explained sum of squares.

The LAR declined appreciably with seedling age; mean calculated LAR values of $31.2 \mathrm{~mm} \cdot \mathrm{mg}^{-1}$ were found on Day 12 compared with $21.6 \mathrm{~mm}^{2} \cdot \mathrm{mg}^{-1}$ on Day 21 . In addition, a significant decrease in LAR with increasing irradiance was apparent: $28.2 \mathrm{~mm}^{2} \cdot \mathrm{mg}^{-1}$ for LI seedlings vs. $24.3 \mathrm{~mm}^{2} \cdot \mathrm{mg}^{-1}$ for HI seedlings. The quadratic temperature term in the LAR regression indicates a minimum LAR at a PMT of 22.5C. ANOVA of LAR data among temperature treatments shows a significantly $(P<0.001)$ larger LAR in the $29 / 29 \mathrm{C}$ treatment than in all other treatments: $30.9 \mathrm{~mm}^{2} \cdot \mathrm{mg}^{-1}$ at PMT $>26 \mathrm{C}$ vs. LAR of 23.7 to $26.8 \mathrm{~mm}^{2} \cdot \mathrm{mg}^{-1}$ at lower PMT. When the data from the 29/29C treatment are deleted from the regression, the quadratic PMT term is no longer significant: $\operatorname{LAR}\left(\mathrm{mm}^{2} \cdot \mathrm{mg}^{-1}\right)=$ 66.6 - 1.08AGE - 0.0358PPF - 0.629PMT; $r^{2}$ (adj.) $=$ 0.79. Thus, with an increase in PMT from 19.6 to $23.9 \mathrm{C}$ (all treatments except 29/29C), the LAR declined significantly.

The larger LAR in the 29/29C treatment are consistent with the results of Warren-Wilson (1966), who found larger LAR as temperature increased in growth studies of sunflower, maize, and rape. Hughes and Evans (1965) found smaller LAR for Impatiens parviflora as light integral increased; our results indicate the same relationship.

Because the LAR data in our study were based on total shoot (i.e., stem and leaves) weight rather than total leaf weight, it is problematic to interpret these LAR results as indicators of leaf thickness. However, if this factor is disregarded, the results suggest leaf thickness increases with age and light intensity and is maximized at intermediate temperatures. Observation of the seedlings grown in the $29 / 29 \mathrm{C}$ treatment substantiate the implications of the LAR data; these seedlings had large, thin, and succulent leaves compared with those grown at intermediate temperatures. These leaf characteristics, coupled with the increased seedling height at high temperatures, are indicators of poor marketable quality with regard to shipping, handling, and transplanting. We believe that these characteristics detract from the quality much more than any added benefit from dry-weight gain at the higher temperature.

\section{Literature Cited}

Dreesen, D.R. and R.W. Langhans. 1991. Uniformity of impatiens plug seedling growth in controlled environments. J. Amer. Soc. Hort. Sci. 116:786-791.

Gardner, F. P., R.B. Pearce, and R.L. Mitchell. 1985. Physiology of crop plants. Iowa Sate Univ. Press, Ames.

Hughes, A.P. 1965. Plant growth and the aerial environment. IX. A synopsis of the autecology of Impatiens parviflora. New Phytol. 64:399-413.

Hughes, A.P. and G.C. Evans. 1965. Plant growth and the aerial environment. II. Effects of light intensity on Impatiens parviflora, New Phvtol. 61:154-174.

Hurd, R.G. and J.H.M. Thomley. 1974. An analysis of the growth of young tomato plants in water culture at different light integrals and CO, concentrations. I. Physiological aspects Ann. Bet. 38:375388 .

Hussey, G. 1965. Growth and development in the young tomato. III: The effect of night and day temperature on vegetative growth. J. Expt. Bot. 16:373-385.

Kessler, R. and A.M. Armitage. 1989. Acceleration of seedling growth of Begonia semperflorens using light, temperature, and carbon dioxide. Res. Rpt. 022, Oct. 1989. Bedding Plants Foundation, Lansing, Mich.

Krizek, D.T., W.A. Bailey, H.H. Klueter. and H.M. Cathey. 1968. Controlled environments for seedling production. Proc. Intl. Plant Prop. Soc. 18:273-281.

Krizek, D.T., W.A. Bailey, H. Klueter, and R.C. Liu. 1974. Maximizing growth of vegetable seedlings in controlled environments at elevated temperature, light, and $\mathrm{CO}_{2}$. Acts Hort. 39:89-101.

Merritt, R.H. and H.C. Kohl, Jr. 1982. Photoperiod and soil temperature effects on crop productivity efficiency and growth of seedling geraniums in the greenhouse. J. Amer. Soc. Hort. Sci. 110(2):204207.

Merritt, R.H. and H.C. Kohl, Jr. 1985. Effect of root temperature and photoperiod on growth and crop productivity efficiency of petunia. J. Amer. Soc. Hort. Sci. 107(6):997-1000.

Merritt, R.H. and H.C. Kohl, Jr. 1989. Crop productivity and morphology of petunia and geranium in response to low night temperature. J. Amer. Soc. Hort. Sci. 114(1):44-48.

Miller, R.O. 1962. Variations in optimum temperatures of snapdragons depending on plant size. Proc. Amer. Soc. Hort. Sci. 81:535-543.

Minitab, Inc. 1988. Minitab reference manual-Release 6. Minitab, Inc., State College, Pa.

Morgan, J. V., P.J. Dempsey, and A. Binchy. 1971. The influence of light, temperature, $\mathrm{CO}_{2}$ concentration, and compost on the development of tomato plants in growing rooms. Acta Hort. 22:164-180.

Seginer, I. and M. Raviv. 1984. Optimal night temperature for greenhouse seedlings. Scientia Hort. 23:203-216.

Shedlosky, M.E. and J.W. White. 1987. Growth of bedding plants in response to root-zone heating and night temperature regimes: J. Amer. Soc. Hort. Sci. 112(2):290-295.

Snedecor, G.W. and W.G. Cochran. 1980. Statistical methods. 7th ed. Iowa State Univ. Press, Ames.

Warren-Wilson, J. 1966. Effects of temperature on net assimilation rate. Ann. Bet. 30:753-761.

Welander, N.T. 1983. Effect of temperature on vegetative and generative development in Pelargonium $\times$ hortorum 'Radio'. Scientia Hort. 21:283-290. 